\title{
UM OLHAR FENOMENOLÓGICO PARA MÃES DE CRIANÇAS VÍTIMAS DE ABUSO SEXUAL: UMA REVISÃO DE LITERATURA
}

\author{
A phenomenological view for mothers of child victims of sexual abuse: a literature review \\ Una mirada fenomenológica a las madres de los niños víctimas de abuso sexual: una revisión de \\ la literatura
}

Gabriela Gibson CunHa Elza Maria Do Socorro Dutra

\begin{abstract}
Resumo: O presente trabalho tem como objetivo lançar um olhar fenomenológico para como as mães de crianças vítimas de abuso sexual são representadas na literatura científica brasileira. Dessa forma, foi realizada uma revisão integrativa de literatura, na qual os estudos foram procurados no banco de dado da Biblioteca Virtual em Saúde (BVS), que inclui outros bancos como o SciElo (Scientific Electronic Library Online), o PePsic (Periódicos Eletrônicos em Psicologia) e a LILACS (Literatura Latino-Americana e do Caribe em Ciências da Saúde). Com isso, foram selecionados 19 artigos no período entre 2006 e 2016. Observou-se que poucos estudos que tivessem como objetivo de pesquisa investigar as mães de vítimas de abuso sexual infantil, além de uma alta concentração desse material no estado do Rio Grande do Sul, sendo o local onde as pesquisas foram mais realizadas. Além disso, não foram encontrados estudos que contemplassem a interface entre o assunto e a fenomenologia. Aponta-se a necessidade de mais estudos que possam contribuir para ampliar a discussão sobre o lugar da mãe diante da vitimização dos filhos.
\end{abstract}

Palavras-chave: Abuso Sexual Infantil; Mãe; Fenomenologia; Revisão de Literatura.

\begin{abstract}
This work aims to present a phenomenological look at how mothers of child victims of sexual abuse are represented in the brazilian scientific literature. An integrative literature review was conducted, in which the studies were searched in the Biblioteca Virtual em Saúde (BVS) database, which includes other banks such as SciELO (Scientific Electronic Library Online), PePsic (Periódicos Eletrônicos em Psicologia) and LILACS (Literatura Latino-Americana e do Caribe em Ciências da Saúde). We selected 19 articles in the period between 2006 and 2016. It was observed that few studies had the objective of investigating the mothers of victims of child sexual abuse, in addition to a high concentration of this material in the state of Rio Grande do Sul, being the place where the surveys were most performed. Furthermore, no studies were found that contemplated the interface between the subject and the phenomenology. It is pointed out the need for more studies that can contribute to broaden the discussion about the place of the mother in relation to the victimization of their children.
\end{abstract}

Keywords: Child Sexual Abuse; Mother; Phenomenology; Literature Review.

Resumen: Este trabajo tiene como objetivo presentar una mirada fenomenológica sobre cómo las madres de niños víctimas de abuso sexual están representadas en la literatura científica brasileña. Por lo tanto, se realizó una revisión integrativa de la literatura, en la cual se realizaron búsquedas en los estudios de la base de datos de la Biblioteca Virtual em Saúde (BVS), que incluye a otros bancos como SciELO (Scientific Electronic Library Online), PePsic (Periódicos Eletrônicos em Psicologia) y LILACS (Literatura Latino-Americana e do Caribe em Ciências da Saúde). Se seleccionaron 19 artículos en el período comprendido entre 2006 y 2016. Se observó que pocos estudios tenían el objetivo de investigar a las madres de víctimas de abuso sexual infantil, además de tener una alta concentración de este material en el estado de Rio Grande do Sul, siendo el lugar donde se realizaron las encuestas más. Además, no se encontraron estudios que contemplaran la interfase entre el sujeto y la fenomenología. Se señala la necesidad de más estudios que puedan contribuir a ampliar la discusión sobre el lugar de la madre en relación con la victimización de sus hijos.

Palavras-clave: Abuso Sexual Infantil; Madre; Fenomenologia; Revisión de Literatura.

\section{Introdução}

Nas relações cotidianas, quando se compartilha casos de abuso sexual infantil, é comum que as primeiras impressões sobre a mãe da criança em questão sejam atravessadas pela culpabilização e negligência. Esse pré-julgamento é evidenciado na literatura em que a mãe é rotulada previamente como cúmplice, sem considerá-la como alguém que também precisa de assistência e apoio (Santos \& Dell'Aglio, 2008). Diante do abuso sexual do filho, as mães vão repensar e refletir seu papel enquanto figura materna, além de vivenciarem sentimentos de culpa, tanto pela desproteção, quanto pelo não desempenho de sua função de guardiã do equilí- brio da família (Lima \& Alberto, 2010). Ademais, as mães também vivenciam as repercussões do abuso sexual do filho de diferentes formas, como "negação da violência, não saber em quem confiar, medo e vulnerabilidade, e crença em respostas mágicas” (Lima \& Alberto, 2010, p 135).

Voltando-se um pouco para o fenômeno do abuso sexual, é possível perceber que este possui uma definição um tanto desafiante. Sanderson (2008) caracteriza o fenômeno como de natureza social, por considerá-lo articulado à cultura e ao período histórico em questão, o que dificulta chegar a uma definição universal. Logo, é importante considerá-lo a partir de uma visão sistêmica, que incorpore em seu espectro o contexto social, as rela- 
ções com a comunidade, a individualidade e a história das famílias (Santos \& Dell'Aglio, 2008). Outro fator complicador repousa sobre outras definições englobadas no fenômeno em questão, como o que é criança e o que seria abuso, ou mesmo quanto à maioridade, pois essas dimensões variam de acordo com a cultura a ser considerada (Sanderson, 2008).

Quando o abuso sexual é revelado, o apoio familiar é "imprescindível para o encaminhamento da situação de violência vivida pela criança e pelo adolescente" (Lima \& Alberto, 2010, p 130). Frente a isso, a figura da mãe recebe ênfase diante do cenário do abuso sexual do filho, pois historicamente recebe a função de guardiã do equilíbrio familiar, sendo ela quem mais irá determinar se a criança contará e de que forma isso irá acontecer (Lima \& Alberto, 2010).

Em seu estudo com mães de crianças vítimas de abuso sexual intrafamiliar, Narvaz (2005) discute sobre as posições que essa mulher ocupa, seja de submissão ou resistência, diante da violência sofrida por elas e por suas filhas. Nesse sentido, a autora identificou que essas mulheres possuíam uma concepção de família nos moldes patriarcais, mesmo que esse não tenha sido o modelo que tiveram em sua própria história. Desse modo, a posição de submissão aparecia alinhada ao desejo de manter a coesão familiar, assim como em cumprir a função parental feminina de cuidar do lar e dos filhos. No entanto, a autora revela que o modelo familiar patriarcal fomentou atitudes de submissão, mas também de resistência por parte dessas mulheres.

Essa dualidade também é discutida entre outros autores. Santos e Dell'Aglio (2008) apontam que frente à revelação, algumas mães podem se posicionar no sentido de proteger e apoiar os filhos, procurando realizar a denúncia, enquanto outras podem ter dificuldade em acreditar nos relatos dos filhos, permanecendo vulneráveis e, até mesmo, continuando sob o controle do abusador. A maneira como a mãe vai conduzir a situação, seja enquanto defensora ou negligente, vai ser influenciada caso ela receba apoio assistencial ou não (Lima \& Alberto, 2010).

Para compreender o lugar dessa mãe, é importante considerar a cobrança que recai sobre elas, uma vez que a sociedade exige que as mães sejam figuras amorosas e com um amor incondicional, algo que não contempla situações em que elas se sentem inseguras diante do mundo (Lima \& Alberto, 2010). Martins e Jorge (2010) indicam que atitudes de conivência das mães, frente à violência sexual dentro de sua casa, podem estar relacionadas à intenção de sustentar a estabilidade e segurança, evitando evidenciar um fracasso enquanto mãe e esposa. Os autores além de mencionar o receio com o rompimento familiar, também apontam a "incerteza em relação ao futuro ao ter que enfrentar as exigências da vida sem o marido, o trauma de ter que lidar com a polícia e tribunais e a própria incapacidade de opôr-se a uma violência que ela mesma tenha sofrido” (Martins e Jorge, 2010, p 251).

Debruçando-se sobre esse fenômeno a partir da Analítica da Existência de Martin Heidegger, é possível colocar em reflexão o que se abre como possibilidade para as mães nesse momento em que tanto se deparam com a violência sofrida pelos filhos, mas também com o fim de um projeto de vida. Em seu pensamento, Heidegger compreende o homem enquanto um existente que está no mundo desprovido de determinações prévias - sejam elas de natureza biológica, psíquica, social ou cultural -, assumindo assim sua condição de estar lançado no mundo, sem qualquer garantia ou controle sobre as coisas, portanto, em risco (Camasmie, 2014). Nesse sentido, Heidegger toma o homem como Dasein, sendo marcado pelo caráter de ter de ser e cujas características constitutivas "são sempre modos possíveis de ser e somente isso" (Heidegger, 1927/2011, p 85).

Diante dessa perspectiva, compreende-se que é no próprio existir que as identidades vão se construir e se cristalizar, seja de mãe ou de mulher. É a partir dessa indeterminação e do caráter de poder ser que vão se abrindo outras possibilidades (Feijoo, 2015). Dessa forma, volta-se para pensar na experiência dessas mulheres, imbuídas da necessidade de se posicionarem diante da família, uma vez que são as principais pessoas notificadoras do abuso sexual (Baía, Veloso \& Magalhães, 2013).

A partir do exposto até aqui, nota-se que o abuso sexual vai trazer repercussões para a família da criança e, nesse cenário, a mãe é uma figura de grande importância. Sendo ela, especialmente, uma das principais pessoas a quem o abuso é revelado e cujo manejo com a situação terá repercussão no modo como as crianças vão lidar com suas experiências (Santos \& Dell'Aglio, 2008). Com isso posto, este trabalho tem como objetivo analisar, a partir da perspectiva fenomenológica, como a figura da mãe é apresentada e referida nos estudos sobre abuso sexual infantil realizados no Brasil. Para tanto, optou-se por realizar uma revisão integrativa de literatura, tendo como questionamento norteador: de que modo as mães de crianças vítimas de abuso sexual são abordadas na literatura nacional?

\section{Método}

Como explicitado acima, a partir do objetivo almejado, poderíamos lançar mão de diversos tipos de revisão de literatura, porém foi eleita a revisão integrativa por nos oferecer uma metodologia de caráter mais amplo no que se refere à inclusão de estudos em formatos variados, como empíricos e teóricos, experimentais e não-experimentais (Souza, Silva \& Carvalho, 2010). Além disso, esse tipo de revisão abrange "um vasto leque de propósitos: definição de conceitos, revisão de teorias e evidências, e análise de problemas metodológicos de um tópico particular" (Souza, Silva \& Carvalho, 2010, p 103). Esses mesmos autores apontam seis etapas para a realização da revisão: elaboração da pergunta norteadora (1), busca ou amostragem na literatura (2), coleta de dados (3), análise crítica dos estudos incluídos (4), discussão dos resultados (5) e apresentação da revisão integrativa (6).

O levantamento de dados foi situado na Biblio- 
teca Virtual de Saúde (BVS), a qual inclui bancos como a SciElo (Scientific Electronic Library Online), o PePsic (Periódicos Eletrônicos em Psicologia) e a LILACS (Literatura Latino-Americana e do Caribe em Ciências da Saúde). A busca se restringiu a um período de dez anos, ou seja, de 2006 a 2016. Além disso, destacam-se os descritores utilizados: abuso sexual infantil, abuso sexual criança, mãe, mães, intrafamiliar, extrafamiliar, violência na família, fenomenologia. Com finalidade de se levantar estudos que trouxessem a figura da mãe em seus objetivos, foi realizado o cruzamento dos descritores "mãe" ou "mães” com "abuso sexual infantil” ou "abuso sexual criança”, visto que há um interesse nessa intercessão de assuntos. Os demais descritores eram acrescentados para refinar esta procura, também levando em consideração a intenção de lançar um olhar fenomenológico sobre as produções encontradas.

A busca foi realizada a partir dessas contingências, além da disposição de alguns critérios de inclusão, sendo eles: estudos realizados no Brasil, em língua portuguesa, e que abarcassem a perspectiva das mães diante do abuso sexual de seus filhos. Na filtragem da amostra, foi observada a importância de incluir outros materiais que não colocassem em foco explícito a experiência da mãe, mas que tecessem considerações acerca do seu papel e/ou sua relação com a família após a revelação do abuso. Tal posicionamento ocorreu em decorrência de tais estudos também incorporarem e contribuírem para se compreender como a figura materna é representada diante do fenômeno em questão. Além disso, a busca se restringiu a uma modalidade de produção acadêmica, sendo artigos publicados em periódicos científicos, essa escolha se justifica pela maior acessibilidade e difusão desse tipo de material.

Todo o material encontrado foi organizado em uma planilha, discriminando-se as categorias de análise: autores, ano de publicação, área de conhecimento, tipo de publicação, objetivo, resumo, conclusão, recomendações, instituição sede do estudo. A partir dessa construção, foi possível refinar os critérios de inclusão e, em seguida, resgatar os textos completos dos estudos selecionados.

\section{Resultados}

A partir do delineamento descrito acima, foram encontrados 24 artigos, dos quais cinco não cumpriram os critérios de inclusão citados acima, totalizando 19 trabalhos a serem contemplados nesta revisão. Esse material foi encontrado da seguinte forma entre os bancos de dados: dez artigos na PePSIC, oito na SciELO e apenas um na LILACS.

Os trabalhos se encontram publicados entre 14 periódicos, sendo eles: Aletheia (2), Arquivos Brasileiros de Psicologia (1), Estudos em Psicologia (3), Boletim em Psicologia (1), Revista Interinstitucional de Psicologia (1), Psicologia \& Sociedade (1), Psicologia Clínica (1), Psicologia em Revista (1), Psicologia: Ciência e Profissão (1), Psicologia: Teoria e Pesquisa (1), Psicologia: Teoria e Prática (1), Revista Brasileira de Crescimento e Desenvolvimento $\mathrm{Hu}-$ mano (1), Revista Latino Americana de Enfermagem
(1), Temas em Psicologia (3). Dentre essas revistas, podemos observar que 12 são da área de psicologia, enquanto as duas restantes se dividem nas áreas de Desenvolvimento Humano e Enfermagem.

Quanto ao ano de publicação, não houve nenhuma no ano de 2006 e os dois anos seguintes contaram apenas com uma por ano. A partir de 2009 até 2013 nota-se uma maior produção, nesse intervalo concentram-se $78,9 \%$ das publicações. Nos dois anos seguintes, foram encontradas uma publicação por ano. Observando as regiões onde os estudos foram realizados, é possível observar uma grande concentração no Sul contando com 47,3\% das pesquisas, porém todos provenientes do Rio Grande Sul, enquanto nenhum outro estado sulista aparece no cenário. No Nordeste encontramos $31,5 \%$ das produções, porém com uma maior diversidade na região por contar com pesquisas em quatro estados diferentes, são eles: Paraíba, Pernambuco, Bahia e Ceará. O restante se divide entre Brasília e Pará, ambos com 10,5\% cada.

Em relação ao delineamento de pesquisa, a maior parte utilizou a abordagem qualitativa, totalizando 15 estudos (78,9\%), dos quais 10 utilizaram entrevistas como instrumento, três eram estudos de caso e dois dispuseram de outros métodos. Quanto ao restante dos estudos, 10,5\% eram teóricos, 5,2\% eram de abordagem quantitativa e os outros $5,2 \%$ mesclavam metodologias quantitativas e qualitativas. Ademais, a maioria dos autores não apresentaram de maneira clara quais suas perspectivas teóricas para as pesquisas, em especial, nenhum estudo que abarcasse a leitura fenomenológica sobre o abuso sexual foi encontrado.

Com o levantamento dos objetivos dos estudos, foi possível dividi-los em três categoria principais, sendo a primeira representada por 10,5\% dos trabalhos, contemplando estudos de caracterização do fenômeno do abuso sexual a partir do levantamento de documentos, como prontuários e processos registrados na delegacia e no âmbito jurídico. A partir desse viés, apontam que as mães são as figuras mais presentes na notificação do abuso, embora acabem por não colaborar, caso o abusador seja seu novo companheiro (Baía, Veloso \& Magalhães, 2013). Além disso, sentem-se desamparadas e desprotegidas pela falta de conhecimento e orientação durante os processos jurídicos (Dobke, Santos \& Dell'Aglio, 2010).

A segunda categoria $(63,1 \%)$ conta com trabalhos nos quais a mãe aparece como sujeito de pesquisa, ou seja, são as protagonistas do estudo. Nesse cenário, investigam-se suas percepções, vivências, reação ao conhecimento do abuso do (a) filho (a), a caracterização do suporte materno, assim como uma discussão sobre a maternidade em sua interface com o abuso sexual infantil. Nos estudos que abordam as reações das mães ao tomarem conhecimento da violência acometida a seus filhos, coloca-se que elas reagem a partir de duas dimensões: a da credibilidade e a da ação, sendo reações positivas ou ambivalentes (Mattos \& Lima, 2012; Santos \& Dell'Aglio, 2009). No entanto, aponta-se também uma grande complexidade de elementos 
que vão atravessar a postura que as mães vão assumir, tomando por base suas próprias histórias, o que engloba a rememoração de suas experiências de abuso na infância e como suas mães agiram, falta de um modelo de família protetiva, falta de apoio familiar, dependência emocional e financeira do parceiro abusador, receio do rompimento familiar (Lima \& Alberto, 2010, 2012, 2015; Santos \& Dell'Aglio, 2008, 2009).

Além disso, é importante ressaltar que a revelação do abuso não acontece em um tempo específico, justamente por se caracterizar como um processo, no qual se incluem os momentos antecedentes à revelação - em que a mãe nota mudanças no comportamento das filhas -, a revelação de fato e as suas repercussões para a família (Santos \& Dell'Aglio, 2013). Isso se faz nos casos em que a mãe não é abusadora, pois ela pode desempenhar diversos papéis diante do abuso sexual de seus filhos, como participantes, perpetradoras ou diligentes (Mattos \& Lima, 2012), inclusive podem transitar entre os lugares de cúmplice e de protetora (Santos \& Dell'Aglio, 2009).

Os estudos apresentam um significativo sofrimento das mães diante da situação do abuso sexual dos seus filhos, destacando sentimentos de culpa; também se tornam mais desconfiadas, desamparadas, vulneráveis e apresentam dificuldades em construir novos laços amorosos, além de questionarem seu papel de mãe (Amazonas, Oliveira \& Melo, 2009; Lima \& Alberto, 2010;). O sentimento de culpa pode se desdobrar em ideações suicidas e homicidas (Carvalho, Galvão \& Cardoso, 2009) e a vergonha pode impedi-las de compartilhar o que aconteceu com outros membros da família (Baía, Magalhães \& Veloso, 2014). Em contrapartida, as mães manifestam o desejo e a esperança de verem as filhas enfrentar as repercussões do abuso e de superar essas dores (Carvalho, Galvão \& Cardoso, 2009).
Por fim, na terceira categoria $(26,3 \%)$, encontram-se trabalhos cujo problema de pesquisa recai sobre as relações familiares, abordando o impacto da revelação do abuso na família e na relação entre seus membros. $\mathrm{O}$ ambiente familiar aparece marcado pela ambiguidade, uma vez que se configura como um espaço de insegurança e de proteção (Penso, Costa, Almeida \& Ribeiro, 2009), sendo que a ambivalência também aparece nas relações familiares, entre as mães e os agressores, assim como com as filhas (Pincolini \& Hutz, 2012). Ainda sobre as relações familiares, a fragilidade dos vínculos, principalmente com as mães, torna mais difícil que a revelação do abuso sexual aconteça, reforçando o silêncio (Siqueira, Arpini \& Savegnano, 2011).

Quanto às considerações finais, os estudos trazem de forma mais expressiva a necessidade de políticas públicas que atuem preventivamente com as famílias, incentivando o diálogo e a interação entre os membros, mas também com o acompanhamento no enfrentamento da situação (Siqueira, Arpini \& Savegnago, 2011). Os estudos sugerem que os serviços de acompanhamento devem se estender para outros membros familiares (Carvalho, Galvão, \& Cardoso, 2009; Penso, Costa, Almeida \& Ribeiro, 2009; Santos e Dell'Aglio, 2009; Lima \& Alberto, 2010; Pincolini \& Hutz, 2012). Alguns estudos destacam a importância do acompanhamento principalmente para as mães e a necessidade de maiores estudos que foquem na sua experiência (Dell'Aglio, Moura \& Santos, 2011; Mattos \& Lima, 2012; Lima \& Alberto, 2012; Santos \& Dell'Aglio, 2008, 2013; Baía, Magalhães \& Veloso, 2014). É importante esclarecer que nem todos os trabalhos apontam de que natureza seriam esses acompanhamentos, podendo ser de caráter psicológico, mas também para a orientação e garantia de direitos, durante e após o processo de revelação.

Tabela 1

Quadro Bibliográfico

\begin{tabular}{|c|c|c|c|c|c|}
\hline $\begin{array}{c}\text { Banco de } \\
\text { Dados }\end{array}$ & Título & Autores & Ano & Objetivo & Recomendações \\
\hline PePSIC & $\begin{array}{c}\text { A percepção de } \\
\text { família em vítimas de } \\
\text { abuso sexual } \\
\text { intrafamiliar: estudo } \\
\text { de caso }\end{array}$ & $\begin{array}{l}\text { Pelisolil C, } \\
\text { Teodoro } \\
\text { MLM, } \\
\text { Dell'Aglio } \\
\text { DD. }\end{array}$ & 2007 & $\begin{array}{l}\text { Investigar as } \\
\text { percepções sobre a } \\
\text { família em duas } \\
\text { meninas vítimas de } \\
\text { abuso sexual } \\
\text { intrafamiliar. } \\
\end{array}$ & $\begin{array}{c}\text { Aponta a necessidade de mais } \\
\text { estudos que incluam as relações } \\
\text { familiares, aspecto negligenciado } \\
\text { na literatura nacional. }\end{array}$ \\
\hline PePSIC & $\begin{array}{l}\text { Caracterização do } \\
\text { Suporte Materno na } \\
\text { Descoberta e } \\
\text { Revelação do Abuso } \\
\text { Sexual Infantil }\end{array}$ & $\begin{array}{c}\text { Baía PAD, } \\
\text { Magalhães } \\
\text { CMC, Xavier } \\
\text { MM. }\end{array}$ & 2014 & $\begin{array}{c}\text { Caracterizar o suporte } \\
\text { materno de cinco mães } \\
\text { de meninas vítimas de } \\
\text { abuso sexual. }\end{array}$ & $\begin{array}{l}\text { Indica-se que nos atendimentos às } \\
\text { vítimas de abuso sexual seja } \\
\text { incluindo um levantamento sobre } \\
\text { o suporte materno, assim como } \\
\text { sobre os estilos parentais se } \\
\text { correlacionam a esse suporte. }\end{array}$ \\
\hline SciELO & $\begin{array}{c}\text { Abuso Sexual } \\
\text { Extrafamiliar: } \\
\text { percepções das mães } \\
\text { de vítimas }\end{array}$ & $\begin{array}{l}\text { Antoni C, } \\
\text { Yunes MAM, } \\
\text { Habigzang L, } \\
\text { Koller SH. }\end{array}$ & 2011 & $\begin{array}{c}\text { Trazer contribuições } \\
\text { teóricas e de pesquisa } \\
\text { sobre o abuso sexual } \\
\text { extrafamiliar em } \\
\text { adolescentes, incluindo } \\
\text { a percepção das mães } \\
\text { das vítimas. }\end{array}$ & $\begin{array}{c}\text { Aponta a necessidade de } \\
\text { pesquisas que embasem o } \\
\text { desenvolvimento de políticas } \\
\text { públicas para a prevenção, } \\
\text { proteção e atendimento frente a } \\
\text { violência contra crianças e } \\
\text { adolescentes. }\end{array}$ \\
\hline
\end{tabular}




\begin{tabular}{|c|c|c|c|c|c|}
\hline $\begin{array}{c}\text { Banco de } \\
\text { Dados }\end{array}$ & Título & Autores & Ano & Objetivo & Recomendações \\
\hline SciELO & $\begin{array}{l}\text { Atendimento a mães } \\
\text { de vítimas de abuso } \\
\text { sexual e abusadores: } \\
\text { considerações } \\
\text { teóricas e práticas }\end{array}$ & $\begin{array}{l}\text { Dell'Aglio } \\
\text { DD, Moura A, } \\
\text { Santos SS. }\end{array}$ & 2011 & $\begin{array}{l}\text { Levantar informações } \\
\text { sobre o atendimento } \\
\text { psicológico prestado às } \\
\text { mães de crianças e } \\
\text { adolescentes vítimas de } \\
\text { abuso sexual, bem } \\
\text { como aos autores dessa } \\
\text { violência. }\end{array}$ & $\begin{array}{l}\text { Importância de se incluir as mães } \\
\text { nas intervenções em casos de } \\
\text { abuso sexual infantil. Pouco } \\
\text { interesse em estudar as mães. }\end{array}$ \\
\hline PePSIC & $\begin{array}{l}\text { Repercussões do } \\
\text { abuso sexual } \\
\text { incestuoso sobre a } \\
\text { relação mãe X filha }\end{array}$ & $\begin{array}{l}\text { Amazonas, } \\
\text { MCL, Oliveira } \\
\text { PA, Melo } \\
\text { LMMB. }\end{array}$ & 2009 & $\begin{array}{l}\text { Compreender a relação } \\
\text { entre mães e filhas } \\
\text { após a descoberta e } \\
\text { denúncia do abuso } \\
\text { sexual incestuoso } \\
\text { sofrido pela criança. }\end{array}$ & Não aponta recomendações. \\
\hline PePSIC & $\begin{array}{l}\text { Bem-estar subjetivo } \\
\text { em famílias com } \\
\text { histórico de abuso } \\
\text { sexual intrafamiliar }\end{array}$ & $\begin{array}{l}\text { Pincolini } \\
\text { AMF, Hutz } \\
\text { CS. }\end{array}$ & 2011 & $\begin{array}{l}\text { Avaliou o Bem-Estar } \\
\text { Subjetivo (BES) de } \\
\text { vítimas de abuso } \\
\text { sexual intrafamiliar e } \\
\text { de seus familiares após } \\
\text { a conclusão de } \\
\text { processos judiciais. }\end{array}$ & $\begin{array}{l}\text { Necessidade dos atendimentos se } \\
\text { estenderam a outros membros da } \\
\text { família, incluindo o abusador, } \\
\text { para além das vítimas. }\end{array}$ \\
\hline SciELO & $\begin{array}{l}\text { Abuso sexual infantil: } \\
\text { percepções de mães } \\
\text { em face do abuso } \\
\text { sexual de suas filhas }\end{array}$ & $\begin{array}{c}\text { Carvalho } \\
\text { QCM, Galvão } \\
\text { MTG, } \\
\text { Cardoso } \\
\text { MVLML. } \\
\end{array}$ & 2009 & $\begin{array}{l}\text { Apreender a percepção } \\
\text { de mães cujas filhas } \\
\text { foram vítimas de abuso } \\
\text { sexual infantil. }\end{array}$ & $\begin{array}{l}\text { Importância do acompanhamento } \\
\text { da família, além da vítima. }\end{array}$ \\
\hline SciELO & $\begin{array}{l}\text { O olhar das mães } \\
\text { acerca do abuso } \\
\text { sexual intrafamiliar } \\
\text { sofrido por suas filhas }\end{array}$ & $\begin{array}{l}\text { Lima JÁ, } \\
\text { Alberto MFP. }\end{array}$ & 2015 & $\begin{array}{l}\text { Concepções que as } \\
\text { mães possuem acerca } \\
\text { do abuso sexual sofrido } \\
\text { por suas filhas. }\end{array}$ & $\begin{array}{c}\text { Ressalta a importância de } \\
\text { políticas públicas que possam } \\
\text { servir de suporte para lidar com a } \\
\text { situação, no sentido de orientação } \\
\text { e garantia de direitos. }\end{array}$ \\
\hline SciELO & $\begin{array}{c}\text { Abuso sexual } \\
\text { intrafamiliar: as mães } \\
\text { diante da vitimação } \\
\text { das filhas }\end{array}$ & $\begin{array}{c}\text { Lima JÁ, } \\
\text { Alberto MFP. }\end{array}$ & 2012 & $\begin{array}{l}\text { Apreender a forma com } \\
\text { que as mães se expõem } \\
\text { subjetivamente diante } \\
\text { do conhecimento do } \\
\text { abuso sexual } \\
\text { intrafamiliar das filhas. }\end{array}$ & $\begin{array}{l}\text { O acompanhamento e suporte às } \\
\text { mães se faz necessário não só por } \\
\text { sua experiência de sofrimento, } \\
\text { mas por serem uma figura } \\
\text { importante para a revelação ou } \\
\text { não do abuso e também por seu } \\
\text { apoio aos filhos. }\end{array}$ \\
\hline PePSIC & $\begin{array}{l}\text { O processo de } \\
\text { revelação do abuso }\end{array}$ & $\begin{array}{l}\text { Santos SS, } \\
\text { Dell'Aglio } \\
\text { DD }\end{array}$ & 2013 & $\begin{array}{l}\text { Investigou o processo } \\
\text { de revelação do abuso }\end{array}$ & $\begin{array}{l}\text { Necessidade de fortalecer serviços } \\
\text { de acompanhamento para essas } \\
\text { situações e pesquisas, sobretudo }\end{array}$ \\
\hline PePSIC & $\begin{array}{c}\text { A percepção de } \\
\text { família em vítimas de } \\
\text { abuso sexual } \\
\text { intrafamiliar: estudo } \\
\text { de caso }\end{array}$ & $\begin{array}{l}\text { Pelisolil C, } \\
\text { Teodoro } \\
\text { MLM, } \\
\text { Dell'Aglio } \\
\text { DD. }\end{array}$ & 2007 & $\begin{array}{l}\text { Investigar as } \\
\text { percepções sobre a } \\
\text { família em duas } \\
\text { meninas vítimas de } \\
\text { abuso sexual } \\
\text { intrafamiliar. }\end{array}$ & $\begin{array}{c}\text { Aponta a necessidade de mais } \\
\text { estudos que incluam as relações } \\
\text { familiares, aspecto negligenciado } \\
\text { na literatura nacional. }\end{array}$ \\
\hline PePSIC & $\begin{array}{l}\text { Caracterização do } \\
\text { Suporte Materno na } \\
\text { Descoberta e } \\
\text { Revelação do Abuso } \\
\text { Sexual Infantil }\end{array}$ & $\begin{array}{l}\text { Baía PAD, } \\
\text { Magalhães } \\
\text { CMC, Xavier } \\
\text { MM. }\end{array}$ & 2014 & $\begin{array}{c}\text { Caracterizar o suporte } \\
\text { materno de cinco mães } \\
\text { de meninas vítimas de } \\
\text { abuso sexual. }\end{array}$ & $\begin{array}{l}\text { Indica-se que nos atendimentos às } \\
\text { vítimas de abuso sexual seja } \\
\text { incluindo um levantamento sobre } \\
\text { o suporte materno, assim como } \\
\text { sobre os estilos parentais se } \\
\text { correlacionam a esse suporte. }\end{array}$ \\
\hline SciELO & $\begin{array}{l}\text { Abuso Sexual } \\
\text { Extrafamiliar: } \\
\text { percepções das mães } \\
\text { de vítimas }\end{array}$ & $\begin{array}{l}\text { Antoni C, } \\
\text { Yunes MAM, } \\
\text { Habigzang L, } \\
\text { Koller SH. }\end{array}$ & 2011 & $\begin{array}{l}\text { Trazer contribuições } \\
\text { teóricas e de pesquisa } \\
\text { sobre o abuso sexual } \\
\text { extrafamiliar em } \\
\text { adolescentes, incluindo } \\
\text { a percepção das mães } \\
\text { das vítimas. }\end{array}$ & $\begin{array}{l}\text { Aponta a necessidade de } \\
\text { pesquisas que embasem o } \\
\text { desenvolvimento de políticas } \\
\text { públicas para a prevenção, } \\
\text { proteção e atendimento frente a } \\
\text { violência contra crianças e } \\
\text { adolescentes. }\end{array}$ \\
\hline
\end{tabular}




\begin{tabular}{|c|c|c|c|c|c|}
\hline $\begin{array}{c}\text { Banco de } \\
\text { Dados }\end{array}$ & Título & Autores & Ano & Objetivo & Recomendações \\
\hline SciELO & $\begin{array}{l}\text { Atendimento a mães } \\
\text { de vítimas de abuso } \\
\text { sexual e abusadores: } \\
\text { considerações } \\
\text { teóricas e práticas }\end{array}$ & $\begin{array}{l}\text { Dell'Aglio } \\
\text { DD, Moura A, } \\
\text { Santos SS. }\end{array}$ & 2011 & $\begin{array}{l}\text { Levantar informações } \\
\text { sobre o atendimento } \\
\text { psicológico prestado às } \\
\text { mães de crianças e } \\
\text { adolescentes vítimas de } \\
\text { abuso sexual, bem } \\
\text { como aos autores dessa } \\
\text { violência. }\end{array}$ & $\begin{array}{l}\text { Importância de se incluir as mães } \\
\text { nas intervenções em casos de } \\
\text { abuso sexual infantil. Pouco } \\
\text { interesse em estudar as mães. }\end{array}$ \\
\hline PePSIC & $\begin{array}{l}\text { Repercussões do } \\
\text { abuso sexual } \\
\text { incestuoso sobre a } \\
\text { relação mãe X filha }\end{array}$ & $\begin{array}{l}\text { Amazonas, } \\
\text { MCL, Oliveira } \\
\text { PA, Melo } \\
\text { LMMB. }\end{array}$ & 2009 & $\begin{array}{l}\text { Compreender a relação } \\
\text { entre mães e filhas } \\
\text { após a descoberta e } \\
\text { denúncia do abuso } \\
\text { sexual incestuoso } \\
\text { sofrido pela criança. } \\
\end{array}$ & Não aponta recomendações. \\
\hline PePSIC & $\begin{array}{l}\text { Bem-estar subjetivo } \\
\text { em famílias com } \\
\text { histórico de abuso } \\
\text { sexual intrafamiliar }\end{array}$ & $\begin{array}{l}\text { Pincolini } \\
\text { AMF, Hutz } \\
\text { CS. }\end{array}$ & 2011 & $\begin{array}{l}\text { Avaliou o Bem-Estar } \\
\text { Subjetivo (BES) de } \\
\text { vítimas de abuso } \\
\text { sexual intrafamiliar e } \\
\text { de seus familiares após } \\
\text { a conclusão de } \\
\text { processos judiciais. }\end{array}$ & $\begin{array}{l}\text { Necessidade dos atendimentos se } \\
\text { estenderam a outros membros da } \\
\text { família, incluindo o abusador, } \\
\text { para além das vítimas. }\end{array}$ \\
\hline SciELO & $\begin{array}{l}\text { Abuso sexual infantil: } \\
\text { percepções de mães } \\
\text { em face do abuso } \\
\text { sexual de suas filhas }\end{array}$ & $\begin{array}{l}\text { Carvalho } \\
\text { QCM, Galvão } \\
\text { MTG, } \\
\text { Cardoso } \\
\text { MVLML. }\end{array}$ & 2009 & $\begin{array}{l}\text { Apreender a percepção } \\
\text { de mães cujas filhas } \\
\text { foram vítimas de abuso } \\
\text { sexual infantil. }\end{array}$ & $\begin{array}{l}\text { Importância do acompanhamento } \\
\text { da família, além da vítima. }\end{array}$ \\
\hline SciELO & $\begin{array}{c}\text { O olhar das mães } \\
\text { acerca do abuso } \\
\text { sexual intrafamiliar } \\
\text { sofrido por suas filhas }\end{array}$ & $\begin{array}{l}\text { Lima JÁ, } \\
\text { Alberto MFP. }\end{array}$ & 2015 & $\begin{array}{c}\text { Concepções que as } \\
\text { mães possuem acerca } \\
\text { do abuso sexual sofrido } \\
\text { por suas filhas. }\end{array}$ & $\begin{array}{c}\text { Ressalta a importância de } \\
\text { políticas públicas que possam } \\
\text { servir de suporte para lidar com a } \\
\text { situação, no sentido de orientação } \\
\text { e garantia de direitos. }\end{array}$ \\
\hline SciELO & $\begin{array}{c}\text { Abuso sexual } \\
\text { intrafamiliar: as mães } \\
\text { diante da vitimação } \\
\text { das filhas }\end{array}$ & $\begin{array}{c}\text { Lima JÁ, } \\
\text { Alberto MFP. }\end{array}$ & 2012 & $\begin{array}{l}\text { Apreender a forma com } \\
\text { que as mães se expõem } \\
\text { subjetivamente diante } \\
\text { do conhecimento do } \\
\text { abuso sexual } \\
\text { intrafamiliar das filhas. }\end{array}$ & $\begin{array}{l}\text { O acompanhamento e suporte às } \\
\text { mães se faz necessário não só por } \\
\text { sua experiência de sofrimento, } \\
\text { mas por serem uma figura } \\
\text { importante para a revelação ou } \\
\text { não do abuso e também por seu } \\
\text { apoio aos filhos. }\end{array}$ \\
\hline PePSIC & $\begin{array}{l}\text { O processo de } \\
\text { revelação do abuso }\end{array}$ & $\begin{array}{l}\text { Santos SS, } \\
\text { Dell'Aglio } \\
\text { DD } \\
\end{array}$ & 2013 & $\begin{array}{l}\text { Investigou o processo } \\
\text { de revelação do abuso }\end{array}$ & $\begin{array}{l}\text { Necessidade de fortalecer serviços } \\
\text { de acompanhamento para essas } \\
\text { situações e pesquisas, sobretudo }\end{array}$ \\
\hline
\end{tabular}

\section{Discussão}

Retomando um pouco o pensamento de Heidegger, o ser-aí tem o caráter de poder-ser, de maneira a poder assumir o modo de ser da propriedade ou da impropriedade, ou seja, nesse movimento de existir o ser-aí é "sempre essencialmente sua possibilidade, ela pode, em seu ser, isto é, sendo, 'escolher-se', ganhar-se ou perder-se ou ainda nunca ganhar-se ou ganhar-se "aparentemente" (Heidegger, 1927/2011 p. 86). Sobre isso, Camasmie (2014), comentando Heidegger, destaca que não há espaço existencial sem a impropriedade, pois é dela que o ser-aí surge e constantemente retorna, assim, além de caracterizar o modo de ser da cotidianidade, é preciso desfazer-se da noção de que a impropriedade pode ser superada. A autora continua, ainda sobre o modo da impropriedade presente no cotidiano, expondo o caráter de negatividade do ser-aí, que por ser pura possibilidade não é outra coisa senão sua relação de sentido. Essa falta de uma "identidade estável" lhe causa um estranhamento, levando-o a buscar "corresponder aos sentidos aparentemente estáveis e necessários oferecidos pelo mundo" (Casmamie, 2014, p. 125).

É possível refletir que os sentidos que o mundo nos oferece para olhar para as mães de crianças vítimas de abuso sexual, são atravessados pela noção de maternidade idealizada, na qual as mães são as principais responsáveis por melhor cuidar dos filhos, sensível a suas necessidades, paciente e dedicada, possuindo todos os atributos do feminino (Carvalho, Galvão \& Cardoso, 2009). Quando uma mãe falha em corresponder a esse modelo, pode sentir-se culpada e frustrada (Dell'Aglio, Moura \& Santos, 2011), aspecto que é marcante nos estudos encontrados, que destacam o sentimento de culpa vivido pelas mães diante da vitimização dos seus filhos. 
É importante considerar que Heidegger não atribui cargas valorativas a esses modos de ser na propriedade ou impropriedade; na verdade, indica-os enquanto modos legítimos do existir do ser-aí, de maneira que a impropriedade não diz respeito a um grau inferior de desenvolvimento do ser (Camasmie, 2014). Porém, a proposta de se buscar como as mães são retratadas na literatura é justamente um esforço em desnaturalizar o olhar que repousamos a elas cotidianamente, buscando nos aproximar de suas experiências e compreender qual o seu papel nesse cenário e como elas lidam com isso.

Nesse sentido, o que foi encontrado revela o sofrimento dessas mulheres e sua confusão diante não só da violência que seus filhos sofreram, mas também do iminente rompimento familiar. Elas acabam sendo chamadas a se posicionar, uma vez que são as principais pessoas notificadoras do abuso sexual (Baía, Veloso \& Magalhães, 2013). Aqui, cabe pensar sobre o caráter de ter de ser do ser-aí, que seria a virtude essencial de sua existência. A partir dessa compreensão, as características do ser-aí não aparecem como propriedades, mas sim como modos possíveis de ser (Heidegger, 1927/2011).

No entanto, ao assumir uma possibilidade existencial, deixamos de realizar várias outras, ou seja, um "sim" comporta vários "nãos". Assim, nos casos em que o abusador é o companheiro da mãe, decidir realizar a denúncia é dizer "sim" aos filhos e, concomitantemente, dizer "não" ao seu ideal de família e ao seu parceiro amoroso. Frente a essa escolha, a mulher experiencia sentimentos ambivalentes frente a seu papel de mãe e de esposa (Amazonas, Oliveira \& Melo, 2009). Esse poder-ser nos coloca diante de nossa incompletude ontológica e de nossa liberdade constitutiva, que estão circunscritas dentro de um horizonte histórico de sentido, "que tudo aquilo que ele foi, é ou será, depende dos movimentos que empreende na existência junto com os outros" (Camasmie, 2014, p. 139). Os materiais encontrados reforçam essa ideia ao constatar que, ao tomar conhecimento do abuso sofrido pelos filhos, as mães reagem de acordo com suas histórias pessoais (Lima \& Alberto, 2015), o que pode incluir desde suas próprias experiências de abuso na infância até o modelo familiar em que se ancora (Santos \& Dell'Aglio, 2008). Diante desse reconhecimento, elas se encontram desamparadas, perdem suas referências de segurança e se vêem perdidas em sua disponibilidade de confiar em outras pessoas (Lima \& Alberto, 2012), assim como passam a ser mais protetivas com os filhos (Amazonas, Oliveira \& Melo, 2009).

\section{Considerações Finais}

A partir desse trabalho, fica evidente que o abuso sexual na infância é um fenômeno que atinge toda a esfera familiar, em especial a figura da mãe, de quem se espera um posicionamento em relação a como conduzir a situação. Apesar dessa consideração parecer consenso entre os autores, pesquisas que se proponham a estudar essas mulheres ainda são escassas. Ademais, essa produção na literatura aparece concentrada entre poucos autores e dispersa entre poucos estados - apenas sete apresentaram trabalhos publicados. Quanto à interface com a perspectiva fenomenológica, chama a atenção não terem aparecido estudos que se encaixassem nos critérios estabelecidos para essa revisão.

Pode-se afirmar que é expressiva a necessidade de mais estudos que incluam as mães dessas crianças e aprofundem a compreensão sobre sua experiência. São mulheres que, em seu horizonte histórico, deparam-se com um mundo em que a possibilidade de ser com os outros se encontra marcada pela violência de uma forma tão expressiva que se apresenta como um problema sério na contemporaneidade. Além disso, os estudos discutem de forma mais contundente sobre essas mães a partir de suas reações frente à revelação, tomando por base, principalmente, suas histórias pessoais. Tal obliquidade torna possível apontar a pertinência de se levantar discussões que levem em conta as questões de gênero envolvidas nessa situação de violência que acontece, principalmente, dentro do seio familiar e coloca em pauta o lugar e o dever dessas mulheres-mães que falharam naquela que parecia ser sua função mais primordial: a proteção dos filhos e da família.

Por fim, considera-se importante ressaltar as limitações desse estudo, tendo em vista os critérios e o objetivo estabelecidos para a presente revisão. Dessa forma, todas as considerações apresentadas encontram-se circunscritas a essas condições, o que também permite apontar a importância de que outras revisões de literatura possam incluir outros tipos de estudos, como dissertações e teses, a fim de acrescentar à discussão.

\section{Referências}

Amazonas, M., Oliveira, P., \& Melo, L. (2009). Repercussões do abuso sexual incestuoso sobre a relação mãe x filha. Psicologia em Revista, 15(3), 82-100.

Baía, P., Magalhães, C., \& Veloso, M (2014). Caracterização do suporte materno na descoberta e revelação do abuso sexual infantil. Temas em Psicologia, 22(4), 691-700.

Baía, P., Veloso, M., Magalhães, C., \& Dell'Aglio, D. (2013). Caracterização da revelação do abuso sexual de crianças e adolescentes: negação, retratação e fatores associados. Temas em Psicologia, 21(1), 193-202.

Carvalho, Q. Galvão, M., \& Cardoso, M. (2009). Abuso sexual infantil: percepção de mães em face do abuso sexual de suas filhas. Revista Latino-Americana de Enfermagem, 17(4), 501-506.

Camasmie, A. (2014). Psicoterapia de grupo na abordagem fenomenológico-existencial: contribuições heideggerianas. Rio de Janeiro, RJ: Via Verita.

Dobke, V. Santos, S., \& Dell'Aglio, D. (2010). Abuso sexual intrafamiliar: da notificação ao depoimento no contexto processual-penal. Temas em Psicologia, 18(1), 167-176. 
Dell'Aglio, D., Moura, A., \& Santos, S. (2011). Atendimento a mães de vítimas de abuso sexual e abusadores: considerações teóricas e práticas. Psicologia Clínica, 23(2), 53-73.

Feijoo, A. (2015). Solidão, cristalização da identidade feminina e a clínica psicológica existencial. In: A. M. C. Feijoo; M. M. Protasio (Orgs). Situações Clínicas I: Análise Fenomenológica de Discursos Clínicos. Rio de Janeiro, RJ: Edições IFEN.

Heidegger, M. (2011). Ser e Tempo. $5^{\mathrm{a}}$ ed. Petrópolis, R.J: Vozes. Original publicado em 1927.

Lima, J., \& Alberto, M. (2010). As vivências maternas diante do abuso sexual intrafamiliar. Estudos de Psicologia, 15(2), 129-136.

Lima, J., \& Alberto, M. (2012). Abuso sexual intrafamiliar: as mães diante da vitimação das filhas. Revista Psicologia \& Sociedade, 24(2).

Lima, J., \& Alberto, M. (2015). O Olhar de Mães acerca do Abuso Sexual Intrafamiliar Sofrido por suas Filhas. Psicologia: Ciência e Profissão,35(4), 11571170 .

Martins, C., \& Jorge, M. (2010). Abuso sexual na infância e adolescência: perfil das vítimas e agressores em município do sul do Brasil. Texto \& Contexto-Enfermagem, 19(2), 246-255.

Mattos, I., \& Lima, I. (2012). Maternidade eo abuso sexual infantil intrafamiliar: garantir um colo protetor. Revista brasileira de crescimento e desenvolvimento humano, 22(3), 373-377.

Narvaz, M. (2005). Submissão e resistência: explodindo o discurso patriarcal da dominação feminina. Dissertação de Mestrado, Universidade Federal do Rio Grande do Sul.

Pincolini, A., \& Hutz, C. (2012). Bem-estar subjetivo em famílias com histórico de abuso sexual intrafamiliar. Gerais: Revista Interinstitucional de Psicologia, 5(1), 03-22.

Penso, M., Costa, L. Almeida, T., \& Ribeiro, M. (2009). Abuso sexual intrafamiliar na perspectiva das relações conjugais e familiares. Aletheia, (30), 142-157.

Sanderson, C. (2008). Abuso Sexual em Crianças: fortalecendo pais e professores para proteger crianças contra abusos sexuais e pedofilia. M. Books: São Paulo, SP.

Santos, S., \& Dell'Aglio, D. (2008). Compreendendo as mães de crianças vítimas de abuso sexual: ciclos de violência. Estudos de Psicologia, 25 (4), 595-606.

Santos, S., \& Dell'Aglio, D. (2009). Revelação do abuso sexual infantil: reações maternas. Psicologia: teoria e pesquisa. Brasília. Vol. 25, n. 1 (jan/mar 2009), p. 85-92.

Santos, S., \& Dell'Aglio, D. (2013). O processo de revelação do abuso sexual na percepção de mães. Psicolo- gia: teoria e prática, 15(1), 50-64.

Siqueira, A., Arpini, D., \& Savegnago, S. (2011). Família e abuso sexual na perspectiva de adolescentes em situação de vulnerabilidade social. Aletheia, (34), 109-122.

Souza, M., Silva, M., \& Carvalho, R. (2010). Revisão integrativa: o que é e como fazer. Einstein (São Paulo), 8, 102-106.

Gabriela Gibson Cunha é Psicóloga, Graduada pela Universidade Federal do Rio Grande do Norte. Email: gabrielagibson@outlook.com

Elza Maria do Socorro Dutra é Doutora em Psicologia Clínica pela Universidade de São Paulo, Professora Titular de Psicologia na Universidade Federal do Rio Grande do Norte. Email: elzadutra.rn@gmail.com

Recebido em 23.09.2017

Primeira Decisão Editorial em 24.10.2017

Aceito em 20.04.2018 